\title{
CHARACTERISTICS OF SOLID-STATE CALCIUM ION SENSORS BASED ON PHOTOCURABLE AND SELF- PLASTICISING POLYACRYLATE MATRICES
}

\author{
Lee Yook Heng* and Elizabeth A.H. Hall \\ School of Chemical Sciences and Food Technology, Faculty of Science and \\ Technology, Universiti Kebangsaan Malaysia (UKM), \\ 43600 Bangi, Selangor, Malaysia
}

Received 17 November 2005

\begin{abstract}
New membrane materials based on cross-linked poly(n-butyl acrylate) (nBA), have been used successfully as calcium ion-selective membranes. These membrane materials possess selfplasticising property and hence do not require plasticisers. The photocurability and good adhesion characteristics of these polymer matrices enable workable solid-state calcium ion sensors to be fabricated by simple photocure procedures employing the calcium ionophore ETH5234 and a lipophilic additive as ion sensing components. The calcium ion-selectivity of the sensors can be controlled by varying the chemical composition of the photocured membrane. An optimum amount of the cross-linker 2,2-hexanedioldiacrylate (HDDA) and the incorporation of n-heptyl acrylate (nHA) led to improvement in the calcium ion-selectivity. The best calcium ion-selectivity was obtained from a copolymer membrane with composition: nBA $=74 \mathrm{wt}-\%, \mathrm{nHA}=20 \mathrm{wt}-\%$ and HDDA $=0.1 \mathrm{wt}-\%$. The selectivity coefficients of calcium over major cations were: $\log \mathrm{K}_{\mathrm{Ca}, \mathrm{Na}}^{\mathrm{Pot}}=-4.4, \log \mathrm{K}_{\mathrm{Ca}, \mathrm{K}}^{\mathrm{Pot}}=-3.6, \log \mathrm{K}_{\mathrm{Ca}, \mathrm{Li}}^{\mathrm{Pot}}=-5.9, \log \mathrm{K}_{\mathrm{Ca}, \mathrm{Mg}}^{\mathrm{Pot}}=-4.4$ with a Nernstian slope $(29.1 \pm 0.8 \mathrm{mV} /$ decade $)$ under buffered conditions. This potentiometric performance is comparable to other solid-state calcium ion sensors with various plasticised polymer membranes.
\end{abstract}

\section{INTRODUCTION}

Calcium ion is a biological active species that plays a dominating physiological role. Therefore data on ionised calcium activity is superior to total calcium concentration in terms of patient care $[1,2]$. In clinical analyses, where batch to batch calcium ion determination is carried out, ionised calcium is conveniently assayed by using ion-selective electrodes (ISEs) with solvent polymeric membranes and containing a neutral calcium ion carrier [3]. But for continuous in vivo monitoring, ion sensing devices that are miniature and 'dry' are more suitable and a solidstate device for calcium ion monitoring has been developed for in vivo cardiac applications recently $[4,5]$. Other applications of calcium ion sensors include the analysis of Ca content as a nutrient in agriculture and the estimation of water hardness, which is determined from the content of $\mathrm{Ca}$ and $\mathrm{Mg}$, in water quality monitoring.

The transformation of conventional ISEs to miniature and solid-state ion sensors poses several fabrication problems. Among them is the fabrication of the polymeric sensing membrane. The

\footnotetext{
* Corresponding author e-mail: yhl1000@pkrisc.cc.ukm.my
} 
large amount of plasticiser used in a conventional polymer membrane frequently leads to poor adhesion on solid-state substrate surfaces. The non-photocurable characteristics of polymers used further prevents the application of photolithographic method in membrane patterning, a process that is convenient in sensor miniaturisation.

The methacrylate and acrylate type of polymers have been used in the past with the incorporation of plasticisers for the construction of solid-state calcium ion sensors [6 - 10]. The use of polysiloxane membrane matrices were also reported $[11,12]$. The usefulness of the methacrylate and acrylate polymers is attributed to their excellent adhesion on surfaces and their photocurability, which enhances their compatibility with the sensor fabrication process. Unfortunately in the past, these desirable characteristics for sensor fabrication frequently compromised by incorporating a plasticiser in the membrane. Typical problems arised when a plasticiser was incorporated were the inhibition of photocurring processes, plasticiser-polymer incompatibility and the loss of adhesion of the membranes on sensor substrates [7 - 9]. When the methacrylates or epoxy acrylate were used as the main polymer composition, a complete removal of plasticiser was not possible without causing a deterioration in the sensor response. The indispensable nature of plasticiser in these polymer matrices is probably due to the high glass transition temperature $\left(\mathrm{T}_{\mathrm{g}}\right)$ of the methacrylates $[7,8]$ or the aromatic epoxy acrylate polymers [6].

We have shown in our earlier work [13 - 17] that methacrylic-acrylic based polymers can function as ion-selective membrane in the absence of a plasticiser if n-butyl acrylate (nBA) forms the major component of the polymer composition. The $\mathrm{nBA}$ lowers $\mathrm{T}_{\mathrm{g}}$ and hence induces self-plasticising behaviour for the membrane. Apart from $\mathrm{nBA}$, other acrylates with $>4 \mathrm{C}$ linear chain may be useful as polymer matrices since much lower $T_{g}$ could be achieved. Studies have been carried out to examine the effects of variation in the composition of the polyacrylic matrices prepared by photocurring method on the calcium sensor responses, particularly the selectivity behaviour. The results of such studies are reported here.

\section{EXPERIMENTAL}

\subsection{Reagents}

n-Butyl acrylate (nBA), 2-hydroxylethyl methacrylate (HEMA), cross-linker 2hexanedioldiacrylate (HDDA), 2,2,2-trifluoroethyl acrylate (TFEA), photoinitiator 2,2dimethoxy-2-phenylacetophenone (DMPP), o-nitrophenyl octyl ether (NPOE), potassium tetrakis(4-chlorophenyl)]borate (98\%) (KTClPB), chlorides of potassium, sodium, calcium, magnesium, lithium and ammonium (all are analytical grade chemicals), lithium acetate and hexane were from Aldrich, UK. Selectophore grade calcium ionophore, N,N-dicyclohexylN',N'-dioctadecyl-3-oxapentanamide (ETH5234) was obtained from Fluka, UK. n-Heptyl acrylate (nHA) was purchased from Lancaster Chemicals, UK. Tris(hydroxylmethyl)aminomethane (Trizma) and hydrochloric acid were obtained from Sigma, UK. All chemicals were used as received. Standard solutions were prepared by dissolving the analytical grade salts in doubly deionised water that has been purified by an Elgastat UHP water deioniser.

\subsection{Preparation of photocured polyacrylic membranes}

Photocured and self-plasticizing copolymers such as cross-linked poly(n-butyl acrylate) (poly(nBA)), cross-linked poly(n-butyl acrylate-co-n-heptyl acrylate) (poly(nBA-nHA)) and cross-linked poly(n-butyl acrylate-co-2,2,2-trifluoroethyl acrylate) (poly(nBA-TFEA)) were prepared by photopolymerisation procedures as described in the fabrication of calcium ion sensors. The glass transition temperatures $\left(T_{\mathrm{g}} \mathrm{s}\right)$ of the copolymers poly $(\mathrm{nBA})$ and poly $(\mathrm{nBA}-$ 
nHA) were determined by placing $25 \mathrm{mg}$ of a copolymer sample in a Mettler differential scanning calorimeter (DSC) and heating scanned at a rate of $10^{\circ} \mathrm{C} / \mathrm{min}$ from -100 to $100^{\circ} \mathrm{C}$. The $\mathrm{T}_{\mathrm{g}}$ was then determined from the DSC thermogram.

\subsection{Fabrication of solid-state calcium ion sensors}

Solid-state calcium ion sensors were fabricated by depositing through photocurring the appropriate monomers on $\mathrm{Ag} / \mathrm{AgCl}$ discs of size $3.5 \mathrm{~mm}$ radius and $1.0 \mathrm{~mm}$ thick (EOS, Houston, USA). Prior to the deposition of the self-plasticising ion-selective membrane, a layer of poly(hydroxyl-ethyl methacrylate) (pHEMA) was first deposited to act as the innerconducting layer of the sensor. The pHEMA inner layer was deposited by drop coating $3 \mu \mathrm{l}$ of a solution containing $1.6 \%(\mathrm{w} / \mathrm{v})$ of the photoinitiator DMPP in HEMA onto a clean $\mathrm{Ag} / \mathrm{AgCl}$ disc. The photopolymerisation was then carried out in an ultra-violet (UV) exposure unit (RS Ltd., UK) illuminated by two 8 Watts UV tubes that generated UV radiation of $350 \mathrm{~nm}$ as peak output. The mixture was irradiated for 5 min with continuous purging of nitrogen gas. After irradiation, the glassy pHEMA layer formed was rinsed with absolute ethanol to remove traces of unreacted materials. The polymer was allowed to dry before conditioned with $0.1 \mathrm{M}$ of calcium chloride for $1 \mathrm{~h}$.

Calcium ion-selective poly(nBA), poly(nBA-nHA) and poly(nBA-TEFA) membranes were deposited by coating a solution containing mixture of DMPP initiator, HDDA cross-linker, calcium ionophore ETH5234 and lipophilic salt KTCIPB, the monomer nBA, or mixture of nBA-nHA or nBA-TFEA on the hydrated pHEMA layer. All the compositions for the various photocured calcium ion-selective sensor membranes are shown in Table 1. These mixtures (15 $\mu \mathrm{l}$ each) were then photocured according to procedure described for photopolymerisation of pHEMA but with an UV exposure time of $8 \mathrm{~min}$. A membrane that contained no calcium ionophore was also prepared in a similar manner as an experimental control (Table 1).

Table 1: The membrane compositions for solid-state calcium ion sensors prepared by the photocure technique

\begin{tabular}{llllllll}
\hline $\begin{array}{l}\text { Sensor } \\
\text { No. }\end{array}$ & $\begin{array}{l}\text { nBA } \\
(\text { wt-\%) }\end{array}$ & $\begin{array}{l}\text { nHA } \\
(\text { wt-\%) }\end{array}$ & $\begin{array}{l}\text { TFEA } \\
(\text { wt-\%) }\end{array}$ & $\begin{array}{l}\text { HDDA } \\
(\text { wt-\%) }\end{array}$ & $\begin{array}{l}\text { DMPP } \\
(\text { wt-\%) }\end{array}$ & $\begin{array}{l}\text { ETH5234 } \\
(\text { wt-\%) }\end{array}$ & $\begin{array}{l}\text { KTC1PB } \\
\text { (mol-\%) }\end{array}$ \\
\hline 1 & 97.9 & - & - & 0.1 & 1.0 & - & 1.0 (wt-\%) \\
2 & 97.4 & - & - & 0.1 & 1.0 & 1.3 & 8.0 \\
3 & 96.6 & - & - & 0.1 & 1.3 & 1.3 & 47.0 \\
4 & 93.8 & - & - & 0.2 & 1.0 & 4.0 & 48.0 \\
5 & 74.3 & 20.0 & - & 0.2 & 1.0 & 3.5 & 41.0 \\
6 & 74.1 & 20.0 & - & 0.1 & 1.6 & 3.7 & 42.0 \\
7 7\&B & 94.2 & - & - & 0.1 & 1.0 & 3.7 & 42.0 \\
$8 A$ & 64.9 & - & 28.0 & 0.1 & 1.0 & 4.0 & 46.0
\end{tabular}

8B (Same composition as Sensor 8 but with $30 \mathrm{wt}-\%$ of NPOE plasticiser added to the membrane after photocurring)

\subsection{Potentiometric evaluation of calcium ion sensors}

A solid-state calcium ion sensor was first mounted onto a Perspex cell containing a test solution chamber. The constructed sensor is shown in Fig. 1. Conductive epoxy was then applied to the 
back of the sensor for making contact with a shielded cable that was connected to a Jenway 3345 Ion Meter. The reference used for the potentiometric studies was a $\mathrm{Ag} / \mathrm{AgCl}$ electrode with $0.1 \mathrm{M}$ Tris(hydroxylmethyl)aminomethane hydrochloride buffer (Tris. $\mathrm{HCl}, \mathrm{pH}$ 7.5) saturated with $\mathrm{AgCl}$ as internal reference solution and $1.0 \mathrm{M}$ lithium acetate as bridge electrolyte [18]. The difference in potential $(\mathrm{mV})$ between the sensor and the reference was recorded on a Gould BS273 strip chart recorder.

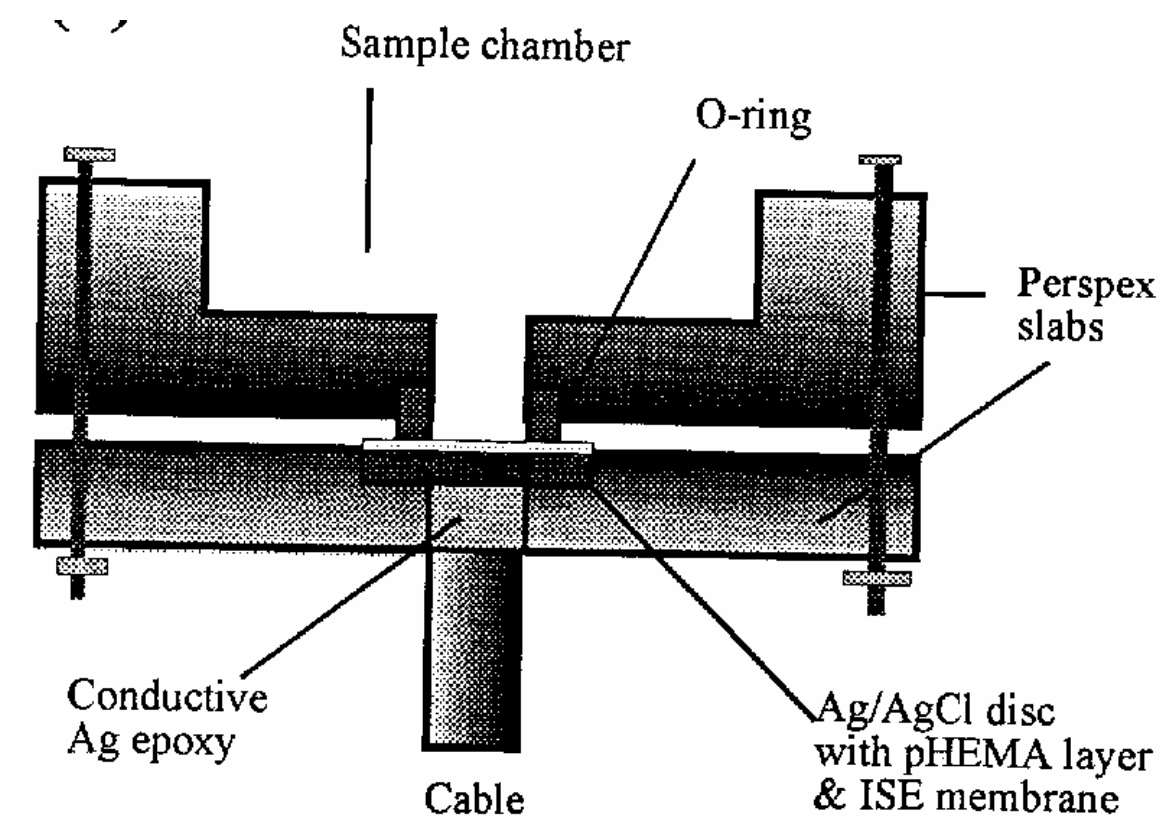

Fig. 1: A diagram showing a construction of the solid-state calcium sensor incorporated in a perplex chamber used for the studies

Standard solutions of calcium ion ranging from $10^{-1}-10^{-7} \mathrm{M}$ were prepared for the evaluation of the calibration curve of the sensor. After exposing each sensor to these standard solutions, the potentiometric response was noted when the electromotive force (emf) changed by $<1.0 \mathrm{mV} / \mathrm{min}$. Six to seven EMF values were obtained and used to plot the calibration curve (emf $(\mathrm{mV})$ vs. logarithmic concentration). Interference studies were carried out by the separate solution method (SSM) and fixed interference method (FIM) with $0.1 \mathrm{M}$ for all interference cations [19, 20]. The SSM was carried out by exposing a new electrode to the interference cations before the primary cation as has been recommended recently $[21,22]$. In between measurements, the electrode was conditioned in doubly deionised water until a stable baseline was obtained. The calculation of selectivity coefficients by SSM were based on Nernstian responses $\left(29.9 \mathrm{mV} /\right.$ decade at $\left.25^{\circ} \mathrm{C}\right)[21$, 22]. For the assessment of interference by $\mathrm{pH}$, solutions of $0.05 \mathrm{M}$ of Tris. $\mathrm{HCl}$ containing a fixed background of calcium ion $(0.05 \mathrm{M})$ with varying $\mathrm{pH}$ values from $2.0-10.0$ were used. The $\mathrm{pH}$ of each solution was measured with an Orion glass $\mathrm{pH}$ electrode. All the measurements were conducted at room temperature $\left(25 \pm 2^{\circ} \mathrm{C}\right)$.

\section{RESULTS AND DISCUSSION}

In photocured membranes for ion sensors, apart from the ionophore and lipophilic salts, various components used in membrane photocurring such as photoinitiator and cross-linker can affect 
the analytical characteristics of the membrane [23]. This is particularly critical if the membrane is to be self-plasticising where its property could no longer be fine tuned using plasticisers. In this case, the fine tuning process relies on the cross-linker HDDA and the use of various monomers. The application of self-plasticising membranes that based on poly(nBA) for monovalent cation sensors have been optimized [23] but such recipe may not be suitable for membrane of a divalent cation sensor like calcium. Therefore, for the fabrication of calcium ionselective membranes, various membrane components were varied in order to obtain an optimum membrane composition for photocurring.

\subsection{Effect of lipophilic sites and ETH5243 on calcium sensor reponse}

From Fig. 2, all poly(nBA) membranes containing ETH5234 ionophore (Sensor No. 2-4, 7B) exhibited selectivity towards calcium ions although the degree of selectivity varied with the membrane compositions. Membrane with no calcium ionophore and contained only KTCIPB (Sensor No.1) did not show any selectivity towards calcium ions but it gave better response to monovalent cations. This shows that even in the absence of plasticiser, the ionophore ETH5234 remained capable of complexing calcium ion selectively. In plasticised PVC membranes, oxapentane-diamide based ionophores like that of ETH5234 have been observed to form 1:3 calcium ion-ionophore complexes [24] and 46 mol- $\%$ of KTClPB was used as the concentration for optimum sensor response [25]. The fact that better calcium ion selectivity was observed when the lipophilic anion concentration was fixed at approximately 40 mol- $\%$ in the poly(nBA) membrane showed that even in the absent of a plasticiser, ETH5234 may be demonstrating complexation behaviour similar to that in plasticised PVC membranes. Comparison of the selectivity patterns of Sensor No. 3 \& 7B showed that variation of ionophore concentrations in the membranes from approximately $1-3 \mathrm{wt}-\%$ (Table 1 ) has little effect on the selectivity of calcium over most other interference cations investigated (Fig. 2).

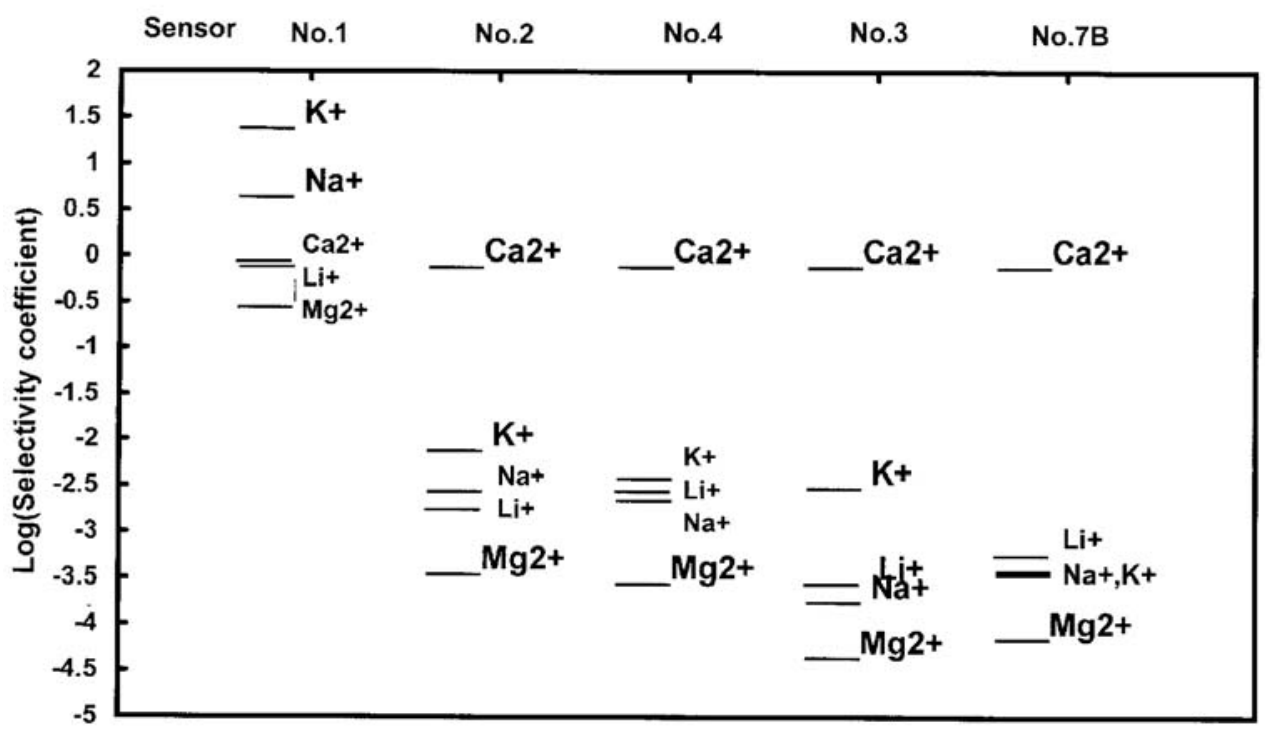

Fig. 2. The effect of changes in compositions of ETH5234 and KTCIPB on the selectivity of the calcium ion sensors fabricated from photocured poly(nBA) membranes. Sensor No. 2, 3, 4 and 7B have varied amount of ETH5234 ionophore and KTCIPB. Sensor No. 1 has no ionophore. (Detail composition of each sensor membrane is shown in Table 1)

However, a reduction of KTCIPB content relative to ETH5234 in Sensor 2 led to a loss of calcium selectivity (Sensor No. 2 cf. Sensor No. 3, Fig. 2), especially the selectivity over that of 
lithium, sodium and magnesium. Lipophilic anion that present in a membrane is known to control the amount of free ionophore available for selective ion complexation [26] and the amount required (relative to the ionophore) is dependence on the type of complexes that formed between the ionophore and the cation involved. The lack of intrinsic anionic sites is a general characteristic of the self-plasticising methacrylic-acrylic membranes $[13,14]$ and has been observed to affect the ideal behaviour of potassium ISEs based on this class of polymer matrices [14]. Perhaps for calcium Sensor 2, the addition of small amount of anionic sites may not be sufficient to induce good membrane response and ionophore selectivity. Obviously, too low an amount of KTClPB in the poly(nBA) membrane is undesirable for a calcium ion-selective poly(nBA) membrane.

\subsection{Effect of cross-linker HDDA on calcium ion sensor}

The increase of cross-linker concentration by a factor of two resulted in an overall reduction of selectivity of calcium ions over other interference ions studied. This is demonstrated by Sensor No. $4 \&$ 7B (Fig. 2) and Sensor No. $5 \& 6$ (Fig. 3). The membrane texture and its $\mathrm{T}_{\mathrm{g}}$ are very much dependent on the amount of cross-linking, which is determined by the amount of HDDA present in the photocure mixture. Increase in the HDDA concentration was observed to yield physically harder membranes, presumably with higher $T_{g}$ when compared with membrane cured with lower amount of HDDA. Perhaps, such change of membrane texture led to loss of ionophore mobility and hence the calcium ion-selectivity deteriorated. Such an observation is in contrast with photocured and plasticised polyurethane membranes where an increase in HDDA content did not result in the loss of selectivity of the sensor [27]. This may be attributed to the presence of a plasticiser in the polyurethane membrane, which compensating for any change in $\mathrm{T}_{\mathrm{g}}$ due caused by the variation in HDDA content.

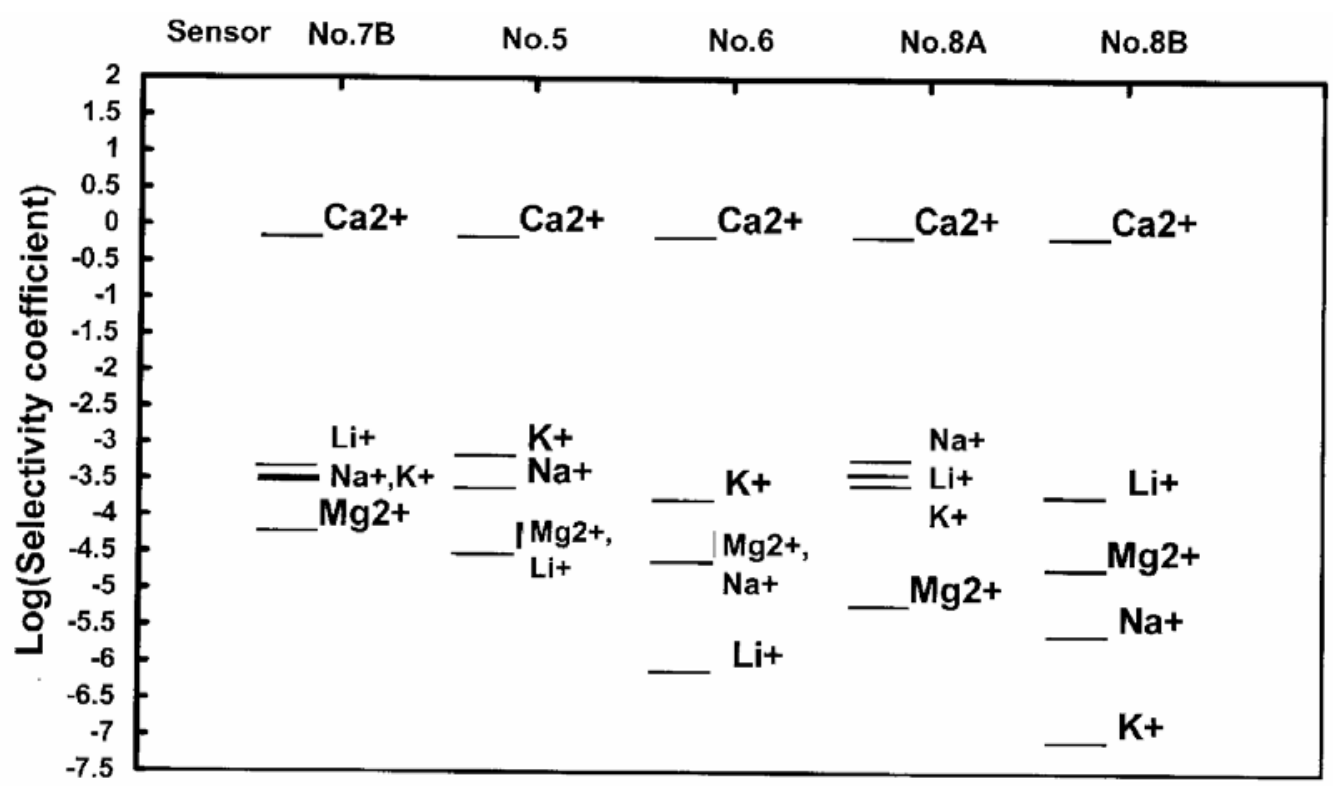

Fig. 3: The variation of selectivity coefficient of calcium ion sensors due to different monomer compositions used for photocurring. Sensor No. 5, 6, 7B and 8A consist of selfplasticised membranes. Sensor No. 8B has membrane composition similar to $8 A$ but NOPE plasticiser has been added. (Detail monomer composition is shown in Table 1) 


\subsection{Effect of monomers on calcium ion sensor response}

Figure 3 depicts the effect of various monomer compositions of the membranes on the calcium ion-selectivity patterns. The selectivity of Sensor No. 7B with a poly(nBA) membrane was largely similar to that of Sensor No. 5 with a membrane containing $20 \mathrm{wt}-\%$ of nHA and twice the HDDA content. This is not surprising considering the similar $\mathrm{T}_{\mathrm{g}} \mathrm{s}$ measured for both of these membranes, i.e. $-44^{\circ} \mathrm{C}$ and $-42^{\circ} \mathrm{C}$ respectively for poly(nBA) and poly(nBA-nHA). Nevertheless, the use of $\mathrm{nHA}$ in the membrane appeared to improve the compatibility of ETH5243 with the resulting membrane as this ionophore was more soluble in a photocure mixture containing nHA than one that contained solely nBA. Membranes with only nBA were slightly cloudy, indicating some extent of crystallisation of a membrane component, probably that of ETH5243. Such incompatibility between the ionophore and the poly(nBA) matrix may be the reason for poorer calcium ion selectivity over lithium ion observed in Sensor 7B compared to Sensor 5. A much larger improvement of calcium ion-selectivity was observed when the amount of cross-linker for the poly(nBA-nHA) membrane of Sensor 6 was reduced (Fig. 3, Table 1). This improvement is likely to be associated with a decrease in $T_{g}$ from the reduction of cross-linking density, although the actual $\mathrm{T}_{\mathrm{g}}$ of this copolymer was not measured.

For a divalent cation sensor, apart from the membrane $T_{g}$, the selectivity behaviour of the ionophore is also affected by the membrane polarity. One of the causes of the reduction of selectivity for divalent cations over monovalent cations is the low membrane polarity. Membranes with higher polarity have been known to yield sensor that could discriminate calcium ion from other monovalent cations [26]. For example, the replacement of a non-polar plasticiser such as di-n-decylphthalate in a photocured epoxyacrylate calcium ion sensor membrane by NPOE led to an improvement of calcium selectivity over monovalent cations by $10-100$ times [9]. Calcium ISE of best performance always required polar plasticiser like NPOE [25]. The dielectric constant of NPOE is $\varepsilon_{\mathrm{r}}=21$ and when mixes with PVC, a polar membrane of $\varepsilon_{\mathrm{r}}=14$ could be achieved [28]. The polyacrylic matrices use in this study may be compared with non-polar polyacrylate materials such as Lucite or Plexiglas. For these materials, the dielectric constants reported were $\varepsilon_{\mathrm{r}}=3-4$ [29]. The non-polar nature of the polyacrylic calcium ion sensor membranes is probably the reason why the selectivity of calcium ion over monovalent cations observed could not surpassed that of a plasticised PVC ISE reported [25].

In an attempt to improve the selectivity of the calcium ion over that of monovalent cations further, 2,2,2-trifluoroethyl acrylate (TFEA) monomers containing polar fluoro groups was included to prepare a copolymer membrane with nBA. The maximum amount of TFEA that could be incorporated is $28 \mathrm{wt}-\%$ because beyond this value, the copolymer began to harden, probably due to an increase in $T_{g}$. Higher $T_{g}$ is anticipated for a copolymer containing TFEA as polymers based on ethyl acrylate alone has higher $T_{g}$ than that based on n-butyl acrylate. The presence of bulky fluoro groups may also contribute to the increase in polymer $T_{g}$ as polymer chain movement may be hindered. Unfortunately the introduction of TFEA did not yield a calcium ion sensor that showed better discrimination against monovalent cations (Sensor No.8A, Fig. 3). The selectivity pattern of calcium over other monovalent cations for this sensor was similar to membrane with nBA alone (Sensor No. 7B, Fig. 3).

Clearly, the introduction of TFEA has not altered the membrane polarity enough to allow a large discrimination between divalent and monovalent cations. To confirm this, $30 \mathrm{wt}-\%$ of the polar plasticiser NPOE was added to the poly(nBA-TFEA) copolymer membrane and left to absorb for $24 \mathrm{~h}$ (Sensor 8B). With the incorporation of NPOE, a large improvement in the selectivity for calcium ions over monovalent cations such as sodium and potassium was observed (Fig. 3). The selectivity coefficients obtained for magnesium, sodium and potassium are comparable to those reported for a plasticised PVC based ISE (Table 2). This implies that the poly(nBATFEA) membrane has polarity lower than poly(nBA-TFEA)/NPOE membrane. A similar attempt to modify the polarity of a non-plasticised polysiloxane membrane for calcium ion- 
selective sensors using polar cyano groups has been performed before [11]. Although the ionophore ETH5234 was also used, the selectivities of calcium ion over monovalent cations such as potassium and sodium did not surpass that of a plasticised PVC membrane [25] but were similar to the values obtained for sensors based on poly(nBA-TFEA) membranes (Table 2).

Table 2: The potentiometric performance of the calcium ion selective sensor based on photocured and self-plasticising poly(nBA-nHA) membrane compared with sensor/ISE based on other polymer membranes and the requirement for blood calcium assay

\begin{tabular}{llllll}
\hline Membrane & $\begin{array}{l}\text { Poly(nBA- } \\
\text { nHA) } \\
\text { (Sensor 6) }\end{array}$ & $\begin{array}{l}\text { Polysiloxane } \\
{[11]}\end{array}$ & $\begin{array}{l}\text { Plasticised } \\
{[25] \text { PVC }}\end{array}$ & $\begin{array}{l}\text { Plasticised } \\
{[32] \mathrm{PVC},} \\
\text { buffered inner } \\
\text { electrolyte }\end{array}$ & $\begin{array}{l}\text { For blood } \\
\mathrm{Ca}^{2+} \text { assay } \\
{[35]}\end{array}$ \\
\hline $\begin{array}{l}\text { Slope } \\
\text { (mV/decade) }\end{array}$ & $29.1 \pm 0.8$ & - & $29.7 \pm 1.7$ & - & - \\
$\begin{array}{l}\text { Linear Range } \\
(-\log \text { ) }\end{array}$ & $1.0-4.0$ & - & $1.0-8.5$ & - & - \\
$\begin{array}{l}\text { Detection } \\
\text { limit (-logC) }\end{array}$ & 5.0 & - & 9.7 & 8.2 & - \\
Selectivity & & & & & \\
coefficient, & & & & & \\
Log(K $\left.\mathrm{K}_{\text {Ca, }}^{\text {pot }}\right)$ & & & & & \\
$\mathrm{j}=$ & & & & & $<-3.6$ \\
$\mathrm{Li}^{+}$ & -5.9 & - & -5.8 & -4.9 & $<-0.6$ \\
$\mathrm{Na}^{+}$ & -4.4 & $<-4.0$ & -5.9 & -6.4 & $<-1.9$ \\
$\mathrm{~K}^{+}$ & -3.6 & $<-3.5$ & -7.5 & -5.6 & -8.6 \\
$\mathrm{Mg}^{2+}$ & -4.4 & $<-3.5$ & -4.4 & -8.6 & \\
\hline
\end{tabular}

\subsection{Effect of pH calcium ion sensor}

The calcium ion sensors based on the self-plasticising polyacrylic membranes demonstrated good calcium ion-selectivity, normal linear response ranges and detection limits but their slopes were slightly super-Nernstian, particularly the slopes for Sensors 2,3,5 and 7a (Table 3, Fig. 4). Super-Nernstian behaviour has been reported for conventional ISEs with non-plasticised silicone rubber membrane $(31.3 \mathrm{mV} /$ decade) [30] and solid contact calcium sensors with photocured plasticised epoxyacrylate membranes $(31.0 \mathrm{mV} /$ decade $-41.8 \mathrm{mV} /$ decade $)[6,9]$. They are various reasons for super-Nernstian behaviour in divalent ion-selective sensors. Among them are the dielectric constant of the membrane, $\mathrm{pH}$ interferences and for solid-state devices and the nature of the conducting substrate. Most recently such behaviour was shown to be due to an excessive influx of the primary ions from the sample phase into the inner electrolyte [31, 32].

In divalent cation sensors, under conditions of low membrane polarity, a divalent cation and a monovalent anion could form a charged associate, which then permeates the membrane as a monovalent cation. This behaviour is expected to be particularly prominent if the sample anion is lipophilic since such anions have greater solubility in the non-polar membrane. The response slope resulting from permeation of charged associate can reach $100 \mathrm{mV} /$ decade [26]. However, 
in the solid-state calcium sensors studied here, no lipophilic sample anion was present in the standard solutions used for evaluating the sensors. Therefore, the super-Nernstian behaviour observed may not be attributed to charged associate although the membranes were non-polar.

Table 3: The potentiometric performances of solid-state calcium sensors with various membrane matrices prepared by photocurring processes

\begin{tabular}{lllll}
\hline $\begin{array}{l}\text { Sensor } \\
\text { No. }\end{array}$ & Membrane type & $\begin{array}{l}\text { Response slope } \\
(\mathrm{mV} / \text { decade })\end{array}$ & Linear $(-\log \mathrm{C})$ & $\begin{array}{l}\text { Rang detection } \\
\operatorname{limit}(-\log )\end{array}$ \\
\hline 1 & Poly(nBA) & $31.0 \pm 0.3$ & $1-4$ & 4.6 \\
2 & Poly(nBA) & $33.2 \pm 0.5$ & $1-5$ & 5.3 \\
3 & Poly(nBA) & $36.2 \pm 0.5$ & $1-5$ & 5.4 \\
4 & Poly(nBA) & $30.4 \pm 0.6$ & $1-5$ & 5.4 \\
5 & Poly(nBA-nHA) & $35.6 \pm 1.1$ & $1-4$ & 5.4 \\
6 & Poly(nBA-nHA) & $29.1 \pm 0.8^{*}$ & $1-4$ & 5.0 \\
$7 \mathrm{~A}$ & Poly(nBA) & $36.6 \pm 0.6$ & $1-4$ & 5.0 \\
$7 \mathrm{~B}$ & Poly(nBA) & $29.9 \pm 1.2^{*}$ & $1-4$ & 4.6 \\
$8 \mathrm{~A}$ & Poly(nBA-TFEA) & $30.1 \pm 1.2^{*}$ & $1-4$ & 4.8 \\
$8 B$ & Poly(nBA-TFEA)/ & $30.7 \pm 2.7^{*}$ & $1-4$ & 4.5 \\
& NPOE plasticiser & & & \\
\hline
\end{tabular}

* Calcium standards were buffered with Tris. $\mathrm{HCl} 0.05 \mathrm{M}, \mathrm{pH} 7$.

Super-Nernstian behaviour for a calcium ion-selective electrode based on PVC/NPOE with the same ionophore was observed below a calcium ion concentration of $10^{-6} \mathrm{M}$ [32]. This behaviour was induced by the presence of a calcium complexing agent in the inner electrolyte which forced the influx of calcium ions towards the inner electrolyte. The super-Nernstian behaviour observed in this work is unlikely to be caused by the excessive influx of calcium ions from the sample phase into the inner electrolyte as the super-Nernstian behaviour observed for most of the sensors did not occur below $10^{-6} \mathrm{M}$. Furthermore the inner solution phase of the sensor, which is a hydrogel with $0.1 \mathrm{M} \mathrm{Ca}$, also did not contained any calcium complexing agent.

A possible reason for the observed super-Nernstian behaviour is interference by $\mathrm{pH}$. For the calcium ion sensors investigated here, changes of $\mathrm{pH}$ from the range $6-10$ were observed to cause a gradual decrease in the emf values $(1.0 \pm 0.1 \mathrm{mV} / \mathrm{pH})$ for a fixed concentration of calcium solution $(0.05 \mathrm{M})$. This is much smaller than $\mathrm{pH}$ interference observed for a calcium ISFET based on a photocured plasticised methacrylate membrane $(12 \mathrm{mV} / \mathrm{pH}$, range $6-10$, $\left[\mathrm{Ca}^{2+}\right]=0.001 \mathrm{M}$ ), which showed no super-Nernstian response although the $\mathrm{pH}$ interference is stronger [7]. This contradicts the observation of this work. Thus, it was necessary to establish whether the super-Nernstian behaviour was the result of interference by $\mathrm{pH}$ since the calcium solutions used in sensor evaluation were not buffered.

The $\mathrm{pH}$ of the unbuffered calcium ion standard solution used in this work were slightly acidic and varied from 5.7 to 6.7 for $10^{-5} \mathrm{M}$ to $10^{-1} \mathrm{M}$ calcium ion. By testing the solid-state calcium sensors using standard calcium solution buffered by $0.05 \mathrm{M}$ Tris. $\mathrm{HCl}$ buffer of $\mathrm{pH}=7$, the slopes obtained for all sensors with different polymer membranes were Nernstian (Table 3 and Fig. 4). Although the $\mathrm{pH}$ appeared to exert interference on the response slopes, it did not show much effect on the selectivity coefficients determined using the FIM or SSM. This can be seen 
in studies carried out on Sensor No. 5 and 7B. For Sensor No. 5, the determination of selectivity coefficients in unbuffered standard solutions by FIM and SSM yielded comparable data. Similar results were obtained for Sensor No.7B where the selectivity coefficients were measured using the SSM under buffered and unbuffered conditions (Table 4).

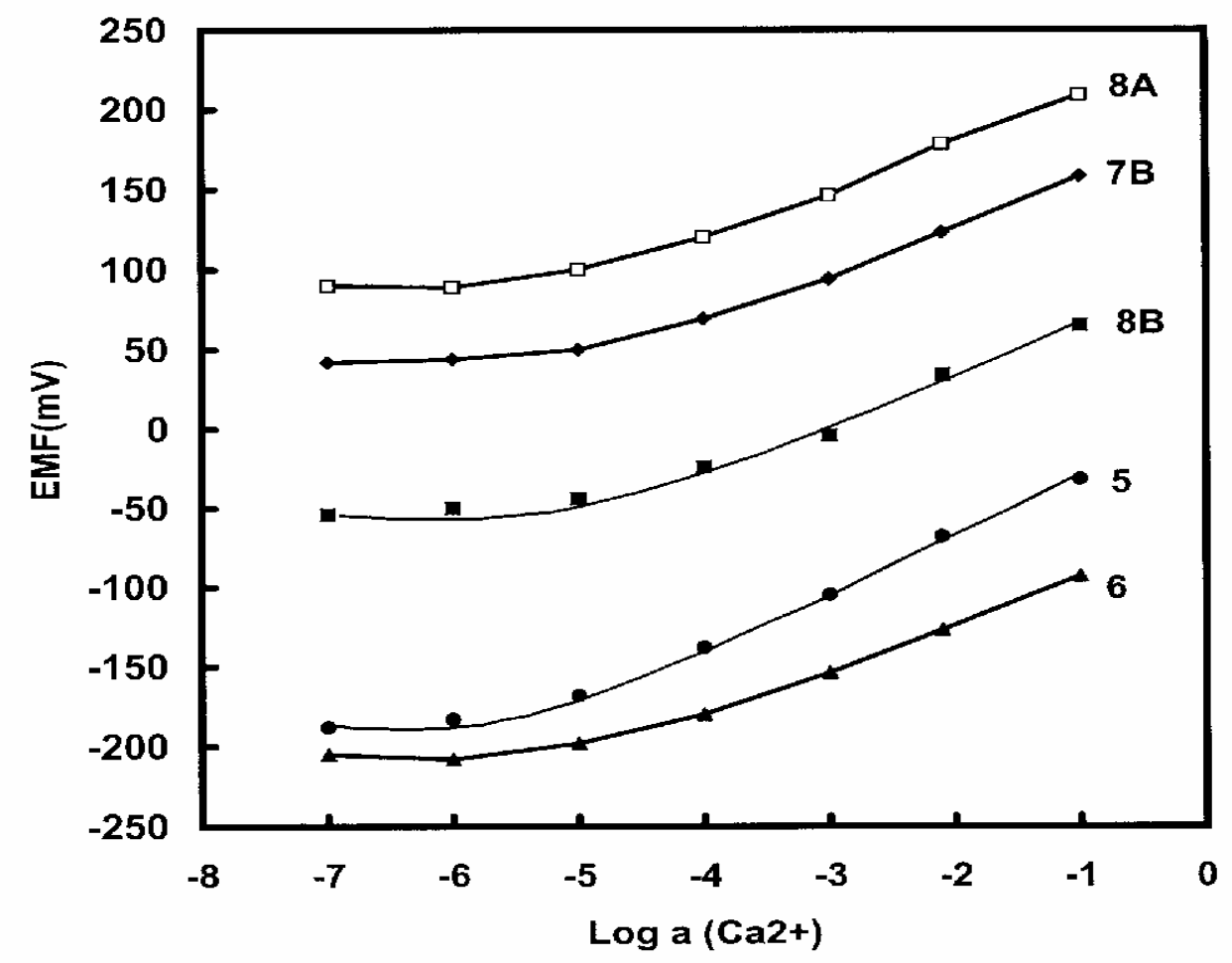

Fig 4: The calcium ion response curves of Sensor No. 5, 6, 7B, 8A and 8B. All the response curves were obtained from standard solutions buffered with Tris. $\mathrm{HCl}(0.05 \mathrm{M}, \mathrm{pH}$ 7) except for Sensor No. 5 which was not buffered (The response slope, linear range and detection limit of each response curve are shown in Table 3)

Table 4: The comparisons of potentiometric selectivity of calcium ion sensors determined by SSM and FIM and under buffered and unbuffered conditions

\begin{tabular}{lcccc}
\hline \multirow{2}{*}{$\log \left(\mathrm{K}_{\mathrm{Ca}, \mathrm{j}}^{\text {pot }}\right)$} & \multicolumn{2}{c}{ Sensor 5 } & \multicolumn{2}{c}{ Sensor 7B } \\
\hline \multicolumn{2}{c}{ *SSM } & *FIM & \multicolumn{2}{c}{$(*$ SSM $)$} \\
\hline $\mathrm{j}=$ & \multicolumn{2}{c}{ (Unbuffered) } & Unbuffered & $*$ *Buffered \\
\hline $\mathrm{Li}^{+}$ & -4.3 & $<-4.0$ & -3.1 & -2.7 \\
$\mathrm{Mg}^{2+}$ & -4.3 & $<-4.2$ & -4.0 & -3.7 \\
$\mathrm{Na}^{+}$ & -3.4 & $<-3.5$ & -3.3 & -3.0 \\
$\mathrm{~K}^{+}$ & -3.0 & -2.9 & -3.3 & -3.1 \\
\hline
\end{tabular}

* Concentration of interference cations $=0.1 \mathrm{M} ; * *$ Buffered with $0.05 \mathrm{M}$ Tris. $\mathrm{HCl}, \mathrm{pH}=7$.

Ionophore itself may contribute to $\mathrm{pH}$ sensitivity of an ISE. The sensitive nature of a calcium ISE to $\mathrm{pH}$ was reported for an ISE with a plasticised PVC membrane incorporated 270 
dialkylphosphoric acid as the sensor. In this case the acidic proton of the dialkylphosphoric acid was responsible for the $\mathrm{pH}$ response. Replacing it by di(octyl-phenyl) phosphate had reduced such interference [33]. For plasticised PVC membrane using diamide calcium ionophores similar to that of ETH5234, $\mathrm{pH}$ interference was not observed in the $\mathrm{pH}$ range of $6-10$ but it occurred at very low $\mathrm{pH}$ values $(<\mathrm{pH}=3)[25,34]$. Thus, for the polyacrylic membranes studied here, it is unlikely that ETH5234 contributed to such $\mathrm{pH}$ interference.

\subsection{Comparison with other calcium sensors}

Comparing the performance of the best calcium sensor (Sensor No. 6) of this work with other published data on calcium sensors/ISEs using the same ionophore (Table 2), the response of Sensor 6 is comparable to a solid-state ISFET device with non-plasticised polysiloxane membrane [11] but the selectivity and detection limit were not as good when compared with ISEs with plasticised PVC membrane. The differences in the selectivity behaviour of Sensor No. 6 and plasticised PVC based ISEs are no doubt attributed to the presence of a plasticiser in the PVC membrane but the use of a liquid or an ion buffer in the inner electrolyte of these ISEs could improve both the detection limits and selectivity of these devices as has been demonstrated recently $[31,32]$. In this work, it has been observed that the selectivity coefficients could be improved by up to $50 \%$ when they were measured prior to exposing the newly made sensor to calcium ion, and the procedure was adopted here in the determination of selectivity. But the inner electrolyte, which was a hydrogel containing $0.1 \mathrm{M}$ calcium ion, remained a source of influx of calcium ion to the surface of the membrane at the sample side. This leads to a poorer selectivity and higher detection limit for the solid-state calcium ion sensor. More study on the hydrogel inner electrolyte in terms of cation flux across the selfplasticised calcium ion-selective membrane may be useful in understanding and improving the sensor characteristics.

In terms of stability, the sensitivity and selectivity of an optimized calcium solid-state sensor varied by $<10 \%$ for a period of 3 months. However, due to the use of a hydrated layer of hydrogel as inner electrolyte (Fig. 1), the offset potential of the electrode may shift when the gel layer dehydrating slowly. Thus, calibration before use of the sensor is necessary.

\section{CONCLUSION}

Self-plasticising acrylic matrices have been successfully employed as membrane materials for solid-state calcium ion sensors. It demonstrates the versatility of the acrylic monomers in manipulating the ion-selective membrane properties to achieve improved sensor performance, particularly the enhancement of calcium ion-selectivity of the sensors. The best calcium ion selectivity was from sensors that based on poly(nBA-nHA) membranes and it has satisfied the requirements for the assay of calcium ions in blood or serum (Table 2) [35]. The process of fabrication of these self-plasticising acrylic membranes by photocurring techniques is simple when compared to other photocurable and non-plasticised membranes reported, which involved more 'chemistry' in terms of manipulating the polymer membrane properties. Clearly, the nonrequirement of plasticisers, photocurability as well as good adhesion property of these n-butyl acrylate based membranes has many advantages over other polymers for ion sensing. Thus, they are a good alternative to the existing membrane materials for solid-state calcium ion sensors.

\section{REFERENCES}

1. Bowers, G.N., Brassard, C., and Sena, S.F. (1986), Clin. Chem., vol. 32, p.1437.

2 Ladenson, J.H. (1983), Anal. Proc., vol. 20, p. 554. 
3 Oesch, U., Ammann D., and Simon, W. (1986), Clin. Chem., vol. 32, p. 1448.

4 Lindner, E., Cosofret, V.V, Ufer, S., Buck, R.P., Kao, W.J., Neuman, M.R., and Anderson, J.M.J. (1994), Biomedical Materials Research, vol. 28, p. 591.

5 Lindner, E., Cosofret, V.V., Buck, R.P., Johnson, T.A., Ash, R.B., Neuman, M.R., Kao W.J., and Anderson, J.M. (1995), Electroanalysis, vol. 7, p. 864.

6 Dimitrakopoulos, T., Farrel, J.R., and Iles, P.J. (1996), Electroanalysis, vol. 8, p. 391.

7 Levichev, S.S., Bratov, A.V., and Vlasov, Y.G. (1994), Sensors and Actuators B, vol.18-19, p. 625 .

8 Moody, G.J., Slater, J.M., and Thomas, J.D.R. (1988), Analyst, vol. 113, p. 103.

9 Cardwell, T.J., Cattrall, R.W., and Iles, P.J. (1985), Anal. Chim. Acta, vol. 177, p. 239.

10 Cattrall, R.W. and Iles, P.J. (1985), Anal. Chim. Acta, vol. 169, p. 403.

11 van der Wal, P.D., van den Berg, A., and de Rooij, N.F. (1994), Sensors \& Actuators B, vol. 18-19, p. 200.

12 Lugtenberg, R.J.W., Egberink, R.J.M., Engbersen, F.J., and Reinhoudt, D.N. (1997), Anal. Chim. Acta, vol. 357, p. 225.

13 Heng, L.Y. and Hall, E.A.H. (1996), Anal. Chim. Acta, vol. 324, pp. 47-56.

14 Heng, L.Y. and Hall, E.A.H. (2000), Anal. Chem., vol. 72, p. 42.

15 Heng, L.Y. and Hall, E.A.H. (2000), Anal. Chim. Acta, vol. 403, p. 77

16 Heng, L.Y. and Hall, E.A.H. (2000), Electroanalysis, vol. 12, p. 178.

17 Heng, L.Y. and Hall, E.A.H. (2000), Electroanalysis, vol. 12, p. 187.

18 Daunert, S. and Bachas, L.G. (1990), Anal. Chem., vol. 62, p. 1428.

19 IUPAC (1994), Pure and Appl. Chem., vol. 66, p. 2527.

20 Moody, G.J. and Thomas, J.D.R. (1971), Selective Ion Sensitive Electrodes. Merrow, England, Chp. 2

21 Bakker, E., Pretsch, E., and Buhlmann, P. (2000), Anal. Chem., vol. 72, p. 1127.

22 Bakker, E., Buhlmann, P., and Pretsch, E. (1999), Electroanalysis, vol. 11, p. 915.

23 Heng, L.Y. and Hall, E.A.H. (2001), Anal. Chim. Acta, vol. 443, p. 25.

24 Ammann, D., Erne, D., Jenney, H.B., Lanter, F., and Simon, W. (1981), In Progress in Enzyme and Ion-Selective Electrodes. Lubbers, D.W., Acker, H., Buck, R.P., Eisenman, G., Kessler M., and Simon, W. (Eds), Springer-Verlag, Germany, p. 9.

25 Gerig, P., Morf, W.E., Welti, M., Pretsch, E., and Simon, W. (1990), Helvetica Chimica Acta, vol. 73, p. 203.

26 Morf, W.E. and Simon, W. (1978), Ion-Selective Electrode Based on Neutral Carriers in Ion-Selective Electrodes in Analytical Chemistry, H. Freiser, Plenum Press, New York, vol. I, Chp. 3.

27 Bratov, A., Abramova, N., Munoz, J., Dominguez, C., Alegret, S., and Bartoli, J. (1995), Anal. Chem., vol. 67, p. 3589.

28 Armstrong, R.D., Wang, H., and Todd, M.J. (1989), J. Electroanal. Chem., vol. 266, p. 173.

29 Lide, D.R. (1994), Dielectric Constants of Some Plastics and Rubbers in CRC Handbook of 
Chemistry and Physics. 75th Edition, CRC Press, Boca Raton, Florida, p. 12.

30 Mostert, I.A., Anker, P., Jenny, H.B., Oesch, U., Morf, W.E., Ammann, D., and Simon, W. (1985), Mikrochimica Acta, 33.

31 Sokalski, T., Zwick, T., Bakker, E., and Pretsch, E. (1999), Anal. Chem., vol. 71, p. 1204.

32 Sokalski, T., Ceresa, A., Fibbioli, M., Zwick, T., Bakker E., and Pretsc, E. (1999), Anal. Chem., vol. 71, p. 1210.

33 Moody, G.J. and Thomas, J.D.R. (1978), Polyvinyl Chloride Matrix Membrane IonSelective Electrodes in Ion Selective Electrodes in Analytical Chemistry, Freiser, H. (Ed), Plenum Press, New York, vol. 1, Chp. 4.

34 Toth, K., Lindner, E., Horvath, M., Jeney, J., Pungor, E., Bitter, I., Agai, B., and Toke, L. (1994), Talanta, vol. 41, p. 1041.

35 Lewenstam, A. (1991), Analytical Proceedings, vol. 28, p. 106. 